Revista de Economia Política, vol. 28, $n^{\circ} 3$ (111), pp. 371-391, julho-setembro/2008

\title{
A globalização no Brasil: responsável ou bode expiatório?
}

\author{
PAULO KLIASS \\ PIERRE SALAMA*
}

Globalization in Brazil: guilty or scapegoat? After the sequence of structural adjustments decisions suggested by the IMF, Brazilian economy became wider opened, as the consequences from financial globalization were stronger than those from commercial globalization. Nevertheless, social and economical reality didn't show much improvement. On the contrary, figures on economic increase and inequalities show Brazil behind the average of developing countries. Even if the effects caused by "mondialisation" on weakened economies are well known, globalization can not be taken as the only guilty of weak economic increase, for maintaining the high level of inequalities or for the increase of precariousness. Responsibility must be searched on high inequalities in where operates "mondialisation", on weakness of public policies, on irresponsible way of opening of the economy and in fiscal policy in favor of financial sector. Other countries have reached quite different results, once the have adopted different public policies, which goal was to establish control and reduction upon the negatives effects of globalization.

Keywords: Brazil, mondialization, globalization; inequalities.

JEL Classification: O11; O19.

Tendo por objetivo a superação da crise de longa duração dos anos 1980, comum a uma série de países em desenvolvimento, os organismos do sistema financeiro internacional propuseram ao Brasil a adoção de uma política econômica inspirada nos modelos da ortodoxia monetarista. Dentre as diversas propostas implementadas, uma estabelecia o aprofundamento da abertura econômica, ou seja, uma elevação do chamado coeficiente de abertura (soma de exportações e importações, em relação ao PIB). Tal medida seria obtida graças a uma redução

\footnotetext{
"Respectivamente, Doutor em Economia e funcionário do Ministério do Planejamento, Orçamento e Gestão, Brasil, e-mail: paulo.kliass@uol.com.br; Doutor em Economia e Professor da Universidade de Paris 13, França, e-mail: salama@seg.univ-paris13.fr. Submetido: Março 2007; Aprovado: Maio 2007.
} 
drástica dos tributos sobre o comércio exterior, a cortes nos subsídios e a uma eliminação das medidas protecionistas não tarifárias, além do fim de restrições existentes à livre circulação de capitais. Este artigo pretende discutir alguns aspectos do processo de mundialização que o Brasil tem vivenciado ao longo dos últimos quinze anos.

As medidas adotadas pelos diferentes desde o fim dos anos 1980 promoveram um aumento no grau de abertura econômica do país. No entanto, a exemplo do ocorrido na grande maioria das economias em desenvolvimento submetidas ao mesmo tratamento de choque, a mundialização financeira cresceu mais rapidamente do que a globalização comercial.

Ao mesmo tempo, a estrutura produtiva do Brasil passou por profundas transformações, de maneira que o país se tornou cada vez mais um exportador de produtos industrializados. Porém, tais exportações eram constituídas de produtos de tecnologia baixa e média. Ao contrário do que se pode observar em várias economias asiáticas, o valor agregado derivado de tais exportações é relativamente fraco e os efeitos em cadeia produzidos no conjunto do complexo econômico estão abaixo do que seriam, caso os setores exportadores fossem portadores de alta tecnologia.

Apesar de o Brasil ter seguido as recomendações das instituições financeiras internacionais, a realidade socioeconômica não apresentou quadro de melhoria. A crise crônica não conseguiu ser superada e assumiu novas formas, além do nível de desigualdades ter permanecido num patamar bastante elevado.

O ritmo de crescimento econômico per capita é muito fraco, em especial se comparado aos países asiáticos, e o nível de transferências efetuadas junto aos setores rentistas e financeiros atinge patamares demasiado elevados. As conseqüências econômicas, sociais e culturais de tal evolução são graves, uma vez que a modernização industrial permanece obstruída pelos aspectos negativos das finanças.

A política monetária extremamente ortodoxa seguida durante os últimos anos tem se caracterizado por taxas de juros reais situadas em níveis dos mais elevados do mundo. Ela favoreceu, por diversas formas, a permanência da economia brasileira em uma tendência de estagnação. Assim, aumentou a diferença entre o nível de investimentos realizados e aquele que seria necessário para atingir o desenvolvimento durável e sustentado. E, como que paradoxalmente, foi essa fraqueza do investimento e do crescimento que permitiu evitar que se aprofundasse a distância entre a demanda e a oferta de mão-de-obra qualificada, desnível esse que poderia ter contribuído ainda a um agravamento das desigualdades salariais. Assim, o Brasil acabou não sofrendo muito os efeitos do nível relativamente insuficiente de suas despesas com educação, pois seu crescimento econômico foi bastante modesto. Basta que este último aumente para que se façam sentir os efeitos negativos da insuficiência dessas despesas públicas. Além disso, caso os comportamentos puramente rentistas dos investidores fossem alterados, o crescimento econômico esbarraria rapidamente nos obstáculos devidos à insuficiência de gastos públicos em termos dos investimentos em infra-estrutura (energia, transportes e outros). $\mathrm{Na}$ verdade, não é a globalização que está na origem do conjunto dos problemas 
encontrados, mas sim a política econômica adotada. Em função de tal política e da estruturação da sociedade brasileira como um organismo profundamente desigual, a globalização apenas faz multiplicar e agravar os aspectos negativos - mas ela não os criou. Pelo contrário, por meio de uma outra política, a globalização permitiria que os aspectos negativos surgidos com abertura econômica se transformassem em seu oposto.

\section{A MUNDIALIZAÇÃO EM NÚMEROS}

O fenômeno que chamamos "mundialização" 1 é resultado de um longo processo de abertura pelo qual tem passado o conjunto das economias ao longo dos tempos. A internacionalização crescente das atividades se traduziu por uma expansão generalizada das trocas, de forma mais ou menos acentuada, segundo as características de cada país. Esta tendência se viu ainda mais reforçada a partir da década de 80. Assim, por exemplo, de acordo com dados do FMI, a porcentagem do total das exportações e importações globais em relação ao PIB mundial passou de $27 \%$ em 1986 a 36\% em 1996, para atingir 50\% em 2006.

Um processo semelhante ocorreu no Brasil. Ainda que o mesmo possa ainda ser considerado uma economia relativamente fechada, caso comparado com o grau atingido pelas economias mais dinâmicas, o fato é que seu grau de abertura aumentou. Entre 1986 e1990, a participação média das trocas comerciais (soma de exportações e importações) em relação ao PIB era de apenas $14 \%$. Ao longo dos últimos cinco anos (2001-2006), tal participação cresceu e se situa em torno de $25 \%$ do PIB, ainda que seja inferior à média mundial e muito aquém de numerosas economias emergentes de crescimento acelerado e da maior parte dos países europeus.

Desde o final do século XX, o processo de globalização se viu reforçado com as novas oportunidades oferecidas ao capital de se valorizar no exterior. Este foi o caso das mudanças profundas que sofreram boa parte dos países em desenvolvimento a partir da privatização de suas empresas estatais e da abertura de seus mercados para os movimentos de capitais, bem como das transformações importantes verificadas nos antigos países do Leste Europeu e na China.

A globalização não é apenas comercial; ela é também financeira. O crescimento da globalização financeira é mais alto que o da globalização comercial. Se nos limitarmos às trocas financeiras e as comparamos às trocas comerciais, pode-se observar que os fluxos de capitais são, em média, cada vez mais importantes em relação aos fluxos comerciais. Em 1986, o estoque de títulos financeiros emitidos representava apenas $23 \%$ do valor dos fluxos comerciais. A participação tende a crescer e desde 2002 esse estoque ultrapassou $2 / 3$ do valor do intercâmbio de comércio, para atingir $71 \%$ no final de 2005 .

\footnotetext{
${ }^{1}$ Neste artigo, nós conferimos o mesmo sentido aos termos "mundialização" e "globalização".
} 
Tal crescimento representa um fortalecimento do peso das atividades puramente financeiras.

No Brasil, o processo se dá em velocidade maior do que a verificada em escala mundial (ver Gráfico 1). Paralelamente à abertura para o intercâmbio de caráter comercial com o resto mundo, assiste-se à elevação dos valores dos títulos meramente financeiros, sobretudo depois de 1994, quando o governo lançou o Plano Real e firmou um acordo com o Fundo Monetário Internacional para a renegociação dos termos da dívida externa do país. Dessa forma, a participação dos títulos financeiros passou de uma média de $8 \%$ antes de 1994 para uma média anual de $60 \%$ para o período seguinte. Ou seja, o aprofundamento da globalização comercial foi acompanhado de uma globalização financeira ainda mais acentuada.

\section{Gráfico 1: Brasil: Evolução da relação "valor total dos títulos financeiros" \\ e "valor total do intercâmbio comercial" (\%)}

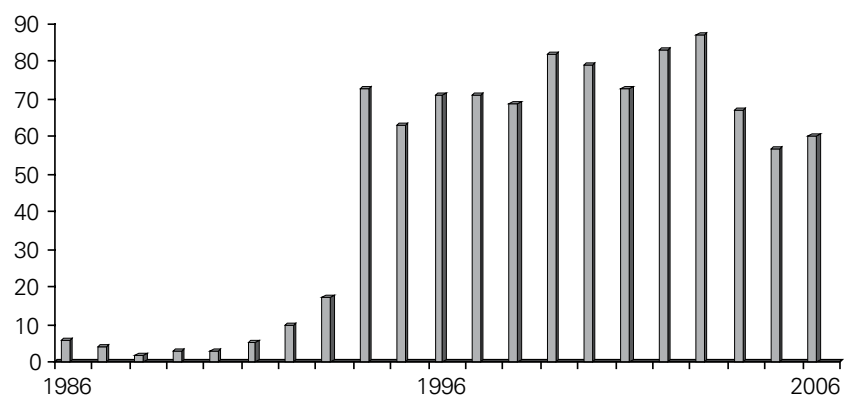

Fonte: Bank for International Settlements (BIS) e Fundo Monetário Internacional (FMI).

O peso crescente da atividade financeira no plano mundial fica ainda mais evidente quando se observa a evolução dos valores dos títulos de caráter financeiro em sua relação com os valores do PIB mundial. Na década de 1980, a participação se situa em torno de $6 \%$ e apresenta um nítido crescimento a partir de 1996, quando passa a $11 \%$, para finalmente atingir $36 \%$ em 2006.

No que se refere ao Brasil (Gráfico 2), observa-se uma estabilidade, entrecortada de ciclos, entre 1986 e 1996, que se explica pela volatilidade elevada do ritmo de crescimento econômico e pelos planos de estabilização ou de renegociação da dívida externa. Logo em seguida, a curva apresenta um crescimento rápido. Assim, a participação dos títulos financeiros sai de uma média de $14 \%$ no primeiro período para atingir uma média de $25 \%$ no segundo período e se mantém em um nível ainda inferior àquele observado para a escala mundial. 


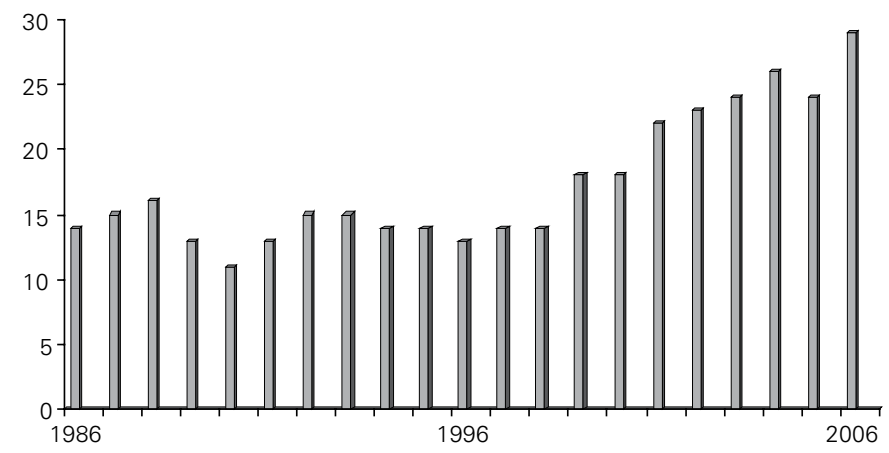

Fonte: Bank for International Settlements (BIS) e Fundo Monetário Internacional (FMI).

A economia brasileira, a exemplo da maioria dos países da América Latina, se caracteriza por um diferencial importante, e crescente desde 2000, entre o ritmo de crescimento de seu PIB e o de suas exportações. O crescimento das exportações não apresentou os efeitos em cadeia sobre o processo de criação geral de riquezas. Caso se considere o ano 1986 (base 100), as exportações atingiram a marca de 615, passados vinte anos. Assim, elas cresceram seis vezes de valor. Já o crescimento atingiu o ponto de apenas 151 em 2006. O contraste é evidente. Portanto, não se pode afirmar que o crescimento das vendas externas tenha promovido o aumento do PIB no Brasil, ao contrário do que se pode deduzir a partir das curvas Exportações/PIB obtidas para os países asiáticos.

As mudanças profundas experimentadas pela economia brasileira se manifestaram também em suas trocas com o resto do mundo. No passado, os setores exportadores dominantes eram sobretudo aqueles ligados aos produtos oriundos do setor primário, ou seja, a agricultura e os minerais. Ao longo dos últimos anos, no entanto, a composição das exportações sofreu alterações profundas: os produtos considerados intermediários (bens semimanufaturados) e alguns produtos de alta tecnologia apresentaram um rápido crescimento relativo.

Durante a década de 1960, por exemplo, o valor total das exportações dos produtos primários correspondia a quatro vezes o valor das exportações dos produtos industrializados $(80 \%$ contra $20 \%)$. Já na década de 1970 , a relação passa de 4:1 para 2:1 em média $(67 \%$ contra $33 \%$ ) e em 1978 a relação atinge a igualdade 1:1. Ao longo dos anos 1980, o total das exportações dos produtos industriais já representa o dobro do total dos produtos de base e, desde a entrada nos anos 1990, essa relação passa a ser de 3:1 (75\% contra $25 \%$ ).

Tal mudança na composição das exportações adquire ainda maior significado quando se decompõe o setor industrial segundo o grau de sofisticação tecnológica incorporado no processo produtivo. Pode-se considerar que dois setores - bens de consumo durável e bens de capital - se caracterizam por apresentar um nível tecnológico mais elevado do que a média dos demais setores da indústria. Esses 
dois setores começam a gerar divisas de forma mais expressiva a partir da década de 1990, quando o total de suas exportações alcança 14\% do total das exportações industriais. Durante os primeiros anos do terceiro milênio tal participação cresce ainda mais e quase dobra, atingindo $27 \%$ no total das exportações de produtos industrializados.

No entanto, é importante observar que tais resultados, por mais promissores que possam parecer, não podem ser considerados suficientes para se concluir por uma visão muito otimista quanto à inserção do Brasil na economia mundial. Isso porque a maior parte das exportações está ainda assentada nos produtos de baixo nível tecnológico ou de baixo valor agregado. O grande salto das exportações brasileiras desde o ano 2000 deveu-se, essencialmente, aos bens manufaturados que incorporam um nível de tecnologia considerado "baixo" ou "baixo-médio", bem como aos produtos não industrializados (aqueles do setor do agronegócios) caracterizados também por baixo valor agregado e nível tecnológico de pouca sofisticação.

São vários os obstáculos a superar nos setores considerados como os mais evoluídos em termos tecnológicos. Até mesmo no caso das exportações da indústria aeronáutica, setor onde a empresa brasileira Embraer é bastante competitiva, os dados relativos à performance exportadora revelam que tais valores mal conseguiram acompanhar o ritmo das exportações totais. ${ }^{2}$

Duas considerações finais são importantes para melhor avaliar a realidade da inserção do Brasil no comércio internacional.

Um dos aspectos mais expressivos do comércio exterior brasileiro relacionase à lenta, mas progressiva, diversificação de seus parceiros comerciais. Tal processo ganha maior significado com o aprofundamento da abertura comercial desde 1990 e se amplia para além das trocas com os países industrializados (Estados Unidos, União Européia e Japão). Verifica-se, assim, um crescimento das vendas para países em desenvolvimento em geral, com especial destaque para os países do Mercosul e a China. Dessa forma, a participação relativa das exportações destinadas aos Estados Unidos, União Européia e Japão caiu de $63 \%$ a $43 \%$ entre 1989-90 e 2005-6 no conjunto das exportações brasileiras. Em sentido contrário, a participação relativa das exportações dirigidas aos países em desenvolvimento aumentou de $27 \%$ a $48 \%$, acusando um crescimento do Mercosul de $4 \%$ a $10 \%$ e da China de $2 \%$ a $6 \%$ para o mesmo período.

O Brasil mantém, em média, uma taxa de crescimento do PIB fraca (cf. supra), mas consegue hoje uma clara melhoria em sua balança comercial graças, principalmente, a um forte aumento em suas exportações. Em 2004, o valor total das exportações atingiu a marca recorde de US $\$ 100$ bilhões, e depois US\$ 118 bilhões em 2005 e US $\$ 137$ bilhões em 2006. As importações mantiveram-se em um nível

\footnotetext{
${ }^{2}$ Ao longo de período 1996-2006, apesar das exportações do setor terem sido multiplicadas por 7, elas continuaram representando no final do período os mesmos $0,2 \%$ das exportações totais que apresentavam no início.
} 
baixo em razão da fraqueza do crescimento econômico e dos investimentos: em 2004 o valor total foi de US\$ 63 bilhões, passando para US\$ 74 bilhões e US\$ 91 bilhões, respectivamente em 2005 e 2006. A balança comercial conseguiu manterse altamente superavitária, o que permitiu a obtenção de um saldo também positivo nas contas correntes e a possibilidade de acumulação expressiva de reservas internacionais. Assim, ao término do primeiro mandato do governo Lula, o Brasil apresentava um total de US\$ 86 bilhões de divisas no final de 2006.

Tal montante de reservas é bastante considerável, em especial quando comparado aos valores dos anos anteriores à vitória de Lula: entre 1999 e 2002, a média anual de reservas registra a cifra de US\$ 36 bilhões. A vulnerabilidade externa parece ter diminuído ao longo dos últimos anos com o crescimento elevado do saldo do comércio exterior e o relativo desempenho das contas correntes. Porém, tal posição ainda apresenta grau razoável de fragilidade pelo valor elevado das saídas de capital devidas ao pagamento de dividendos aos acionistas externos, os quais em 2006 já foram mais elevados do que os pagamentos associados aos juros da dívida externa, tendo atingido a marca de US\$ 17 bilhões. Acrescente-se, por outro lado, que tal vulnerabilidade muda de qualidade, ela se apresenta agora sob outra roupagem. O grau de endividamento interno aumentou consideravelmente e com ele aumentou também o peso dos serviços da dívida interna. Com isso, reduziramse as margens de manobra para uma política fiscal mais audaciosa, no momento em que se faz cada vez mais necessário sair da rota do baixo crescimento, em que o Brasil esteve mergulhado ao longo dos últimos anos. É que o veremos a seguir.

\section{“A GLOBALIZAÇÃO NÃO É A CULPADA”’}

Entre os anos 1950 e 1970, o crescimento foi especialmente sustentado e o grau de abertura econômica parecia bastante fraco em toda a América Latina, em especial no Brasil. Em sentido inverso, a abertura cada vez mais importante, tanto em termos comerciais como financeiros, desde os anos $1990 \mathrm{se} \mathrm{fez} \mathrm{acompanhar}$ por uma desaceleração e por um padrão de irregularidade do crescimento econômico. Tais observações parecem confirmar a existência de uma relação inversa entre abertura e crescimento, ao menos para a América Latina e para o Brasil relação que aparentemente não se encontra em outras regiões do planeta. ${ }^{4}$

\footnotetext{
${ }^{3}$ Nós pegamos emprestado aqui o título da edição francesa do livro de Krugman, P. E aqui utilizamos as expressões "globalização" e "mundialização" de forma alternada, conferindo-lhes um sentido equivalente.

${ }^{4}$ As economias asiáticas são mais abertas e as restrições de competitividade se expressam de forma diversa, em razão de uma relação entre o Estado e a economia diferente daquela existente nas economias latino-americanas. O Brasil ocupa uma posição especial na região: apesar de um aumento considerável em seu grau de abertura econômica ente 1990 (11,7\%) e 2004 (26,9\%), seu peso no comércio internacional permanece marginal e relativamente estável $(1,1 \%$ em 2005 , a mesma porcentagem que em 1975). Já a China atingia 7,4\% em 2005 (contra 0,9\% em 1975, 1,9\% em 1990 e 3,9\% em 2000), cf. carta IEDI, 2006.
} 
No entanto, seria um equívoco considerar que um grau de abertura cada vez mais elevado pudesse explicar por si só a fraqueza do crescimento, assim como seria igualmente um erro considerar, em termos teóricos, que uma grande abertura pudesse automaticamente levar a um crescimento mais sustentado. $\mathrm{Na}$ verdade, tudo depende da natureza das exportações e de seu grau de sofisticação, bem como da forma como elas são estimuladas. ${ }^{5}$

Não é a globalização em si mesma a "culpada" do fraco desempenho do crescimento econômico, da manutenção das desigualdades em niveis tão elevados, nem do crescimento das condições de precariedade de vida da população. A responsabilidade deve ser buscada no contexto (altas desigualdades) em que a mundialização opera, na fraqueza das políticas públicas de apoio, na maneira pela qual se realiza a abertura econômica, enfim na gestão da dívida interna favorecendo as atividades financeiras. O objetivo da presente seção e da seguinte é justamente mostrar que tal ambiente é gerador de comportamentos de tipo rentista. Tais comportamentos assumem formas específicas com o aumento de importância da globalização comercial e da mundialização financeira, na América Latina em geral e no Brasil em particular.

A globalização comercial impõe constrangimentos de competitividade, de qualidade, de organização do trabalho. A mundialização financeira favorece as atividades financeiras em detrimento das atividades produtivas, desvio esse que encontramos em maior ou menor escala na maior parte das economias asiáticas. As duas agem de forma coordenada e os efeitos gerais são: i) uma taxa de crescimento médio fraco ao longo dos últimos anos; ii) uma precarização acentuada nas condições de trabalho; iii) uma distribuição de renda que, apesar de se manter extremamente desigual, muda seus contornos em favor de uma parcela reduzida da população. Após apresentar alguns dados a respeito desse fenômeno, nós analisaremos os efeitos das finanças sobre o investimento e a renda do trabalho, em um contexto de globalização e sob os efeitos das políticas econômicas adotadas. Nós estudaremos, em seguida, os constrangimentos impostos pela globalização

\footnotetext{
${ }^{5}$ As exportações de elevado conteúdo tecnológico se caracterizam por apresentarem uma alta elasticidade da demanda em relação à renda no plano internacional e são capazes de provocar importantes efeitos em cadeia sobre os ramos industriais, à exceção dos casos das "maquiladoras". Dessa forma, elas participam da reorganização profunda do aparato industrial. A ampliação de sua presença não é resultado do livre jogo das forças de mercado, mas da intervenção indireta do Estado, seja no nível da política industrial (política de nichos com taxas de juros preferenciais, subsídios temporários e seletivos etc.), como também no acompanhamento no nível da infra-estrutura física (transportes, energia etc.) e humana (educação, saúde etc.). Tal modo de industrialização é chamado de "vôo de gansos selvagens". Ao contrário, o fraco dinamismo das exportações, as dificultados em promover o salto à frente das exportações de elevada tecnologia constituem modos de crescimento chamados de "patos mancos". Nesse caso, os efeitos sobre o crescimento econômico derivados do salto das exportações são fracos e não se confirma a relação entre maior grau de abertura e forte crescimento da economia.(a respeito dessa questão, ver Lall, 2005, Palma, 2006b e P. Salama, 2006). Na medida em que a participação das exportações de produtos manufaturados de média e alta tecnologias não é ainda significativa no Brasil, pode-se considerar que seu regime de crescimento se assemelhe mais ao modelo do "pato manco" do que dos "gansos selvagens".
} 
sobre as diferentes formas de emprego (qualificado e não-qualificado) e sobre as capacidades de o Estado atender a tais necessidades por meio de uma política educacional conseqüente.

\section{Alguns dados e informações, o Brasil dos últimos quinze anos: a China pega o trem de alta velocidade, o Brasil vai de bicicleta...}

O crescimento econômico apresentou-se especialmente fraco ao longo dos últimos quinze anos. Ele ultrapassa um pouco a taxa média anual de $2,5 \%$ durante o primeiro mandato de Lula e se situa em um patamar comparável ao do segundo mandato do presidente Fernando Henrique Cardoso. ${ }^{6}$ Assim, estamos em face de uma tendência de estagnação econômica. Em sentido oposto, o crescimento econômico é da ordem de $9 \%$ a $10 \%$ em alguns países asiáticos. Ora, é sabido que com $2 \%$ de crescimento é necessário esperar 35 anos para dobrar o Produto Interno Bruto, enquanto com uma taxa de $10 \%$ esse objetivo é atingido em apenas sete anos. Assim, a China teria multiplicado seu PIB por 32 ao longo de 35 anos, ao passo que o Brasil não faria mais do que dobrá-lo no mesmo período. ${ }^{7}$ Ao ritmo de crescimento econômico que a China tem vivido desde 1978, seu Produto Interno Bruto per capita, medido em termos de paridade de poder de compra, ${ }^{8}$ deveria ultrapassar o brasileiro a partir de 2010, ao passo que em 1978 ele era extremamente inferior. O PIB per capita do Brasil em 2005 situava-se em torno de US\$ 8.320, enquanto o chinês era de aproximadamente US\$ 6.600 (fonte: Relatório 2006 do Banco Mundial, anexo estatístico). O PIB per capita do Brasil, em termos de paridade de poder

\footnotetext{
${ }^{6}$ Esse crescimento é ainda mais fraco que aquele observado entre as décadas de 1940 e 1970 . Como ressalta R. Bonelli (Bonelli, R., 2006), o PIB per capita quase quintuplicou entre 1940 e 1980, enquanto ele apenas aumentou 10\% entre 1980 e 2005 (p. 5). Ver também Palma G. (2006b). Observemos ainda que o IBGE acaba de publicar (março 2007) uma reavaliação de sua metodologia de cálculo do PIB, levando em conta um maior peso do setor de serviços. De acordo com as novas ponderações, o crescimento do PIB teria sido $0,6 \%$ mais alto em média durante os três primeiros anos do governo Lula $(3,2 \%)$ do que os cálculos anteriores $(2,6 \%)$. Em sentido contrário, o crescimento relativo ao último mandato de Fernando Henrique Cardoso teria sido mais fraco do que os valores atuais. Acrescente-se ainda que, de acordo com a nova avaliação, a taxa de formação bruta de capital fixo seria particularmente fraca: $16,3 \%$ em lugar de $20,3 \%$, o que reforça ainda mais as características rentistas do modelo brasileiro (cf. supra).

7 A respeito da dança de cadeiras entre as economias asiáticas e as latino-americanas, ver Palma (2006b): o Brasil abandona as altas taxas de crescimento dos anos 1950 a 1970 e as troca por taxas mais baixas nas décadas seguintes. Acrescente-se que a diferença é ainda mais significativa se considerada a medida do PIB per capita: o crescimento demográfico brasileiro foi durante muito tempo mais alto do que o da China e começou a se reduzir de forma mais acentuada apenas nas duas últimas décadas.

${ }^{8}$ Os economistas preferem utilizar a taxa de câmbio de paridade de poder de compra para efeito de comparações internacionais. Na verdade, as taxas reais de câmbio em vigor não representam de forma adequada o poder de compra de suas respectivas moedas quando convertidas em divisas: com um dólar compra-se muito mais na China do que no Brasil ou os Estados Unidos. As taxas de câmbio de paridade têm por objetivo fazer aproximações, de modo que com um dólar se possa comprar as mesmas quantidades de bens, independentemente do país considerado.
} 
de compra, comparado ao dos países da OCDE apresenta uma queda acentuada: em 1980 ele equivalia a 41\% do valor do PIB per capita médio de tais países (com exceção da República Tcheca, da Eslováquia, da Hungria e da Polônia), enquanto passa a representar 28,5\% em 2005 (OCDE, 2005).

As conseqüências de natureza social dessa tendência à estagnação econômica são importantes: dado que o crescimento é fraco, torna-se extremamente reduzida a probabilidade de uma maior mobilidade social e vice-versa. A menos que haja um esforço sem precedentes na área da educação e de uma diminuição significativa das desigualdades por meio de políticas de redistribuição de renda, o que não parece ser o caso até o momento, as chances de uma criança nascida pobre deixar de sê-lo ao longo de sua vida são bastante baixas. Na melhor das hipóteses, podese esperar uma leve melhoria no seu nível de renda.$^{9}$ Com um crescimento mais sustentado, surge uma probabilidade mais elevada de uma mobilidade intergeracional mais acentuada: uma criança nascida pobre pode obter uma melhoria em seu nível de renda, de maneira a abandonar os limites da pobreza. ${ }^{10} \mathrm{Tal}$ melhoria é fruto do aumento da renda média e da possibilidade mais efetiva de ter acesso, caso o sistema educacional assim o permita, a um conjunto mais amplo de formações profissionais qualificadas.

\section{A modernização industrial dificultada pelo fortalecimento das finanças}

A liberalização promoveu a desorganização do tecido industrial, sem que tenham sido colocadas em prática políticas públicas de acompanhamento social. Ao provocarem a eliminação de setores inteiros do aparato industrial, quando foram atingidos os mais frágeis pela crise hiperinflacionária dos anos 1980 (a "década perdida", segundo a CEPAL), a liberalização do comércio exterior e a entrada de investimentos estrangeiros diretos também contribuíram, sem dúvida, para a modernização de uma parte do tecido industrial brasileiro. ${ }^{11}$ As empresas que conseguiram resistir à concorrência externa tiveram êxito em manter um nível de produtividade elevado, apesar das dificuldades enfrentadas durante a "déca-

\footnotetext{
${ }^{9} \mathrm{Em}$ termos ainda mais precisos, as possibilidades de ascensão social são reservadas a alguns raros escolhidos: jogadores de futebol, artistas, políticos e, por fim, os criminosos.

${ }^{10}$ É preciso recordar que nas economias em desenvolvimento a pobreza é medida em termos absolutos: são declarados pobres aqueles indivíduos cujo rendimento monetário não permite adquirir uma determinada quantidade mínima de produtos alimentares e serviços necessários à sua sobrevivência. Assim, a pobreza pode ser reduzida caso o crescimento econômico seja sustentado. Em sentido oposto, o agravamento das desigualdades torna ainda mais difícil a diminuição do nível de pobreza. Esses dois efeitos atuam em sentidos contrários. Se o crescimento econômico é forte e se ele se dá num ambiente de redução sensível das desigualdades, esse nível de pobreza absoluta poderá baixar rapidamente até seu desaparecimento. Nos países desenvolvidos, a pobreza é medida de outra forma: ela pode ser diminuída, mas não pode ser eliminada, uma vez que ela é definida a partir da distribuição de renda em termos relativos. A referência sendo sempre uma sociedade em que cada indivíduo, cada família, recebesse o mesmo rendimento.

${ }^{11}$ Ver Zettelmeyer J., 2006 para um survey da literatura sobre essa questão.
} 
da perdida”, e puderam mesmo aperfeiçoá-lo ainda mais ao longo da década de 1990. A modernização de determinados setores da indústria recebeu a "ajuda”, no início, por conta das maxidesvalorizações cambiais, ${ }^{12}$ mas foi a modificação das técnicas de produção (facilitada pela importação de equipamentos incorporando o progresso técnico mais recente, a custos reduzidos graças à redução tarifária e à posterior apreciação da moeda nacional) e sobretudo a forma de produzir (modificação na organização do trabalho com maior flexibilidade da mão-de-obra) que explicam a reversão da balança comercial brasileira no começo dos anos 2000 e a dinamização da exportação de seus produtos manufaturados, analisada na primeira parte do artigo. As análises de Lall (2005) e Palma (2006c) mostraram, por outro lado, que a alta das exportações de produtos industriais brasileiros deu-se com base nos bens de média e de baixa tecnologias, com apenas algumas exceções (ver abaixo), ao contrário do ocorrido nos países asiáticos, onde se observou um crescimento mais acelerado dos bens de média e alta tecnologias.

Assim, pode-se afirmar que o fortalecimento da modernização foi real, mas relativamente insuficiente em relação à estruturação e à evolução do comércio internacional, focado cada vez mais na compra/venda de produtos de alta tecnologia. O Brasil assiste ao aumento de seu atraso em face dos "dragões" asiáticos, como a Coréia do Sul, e cada vez mais se define um cenário de incapacidade de concorrer com a China e a com Índia, em um futuro próximo, nos mercados ditos promissores. ${ }^{13}$ Tal distanciamento relativo é a conseqüência lógica dos novos comportamentos rentistas.

A atividade financeira pode ser vista como a representação de Jano, com duas caras. Ela possui um lado virtuoso, uma vez que facilita a acumulação, mas pode apresentar também sua faceta parasitária, quando se realiza em detrimento da mesma. Estas duas faces coexistem, sendo uma mais preponderante que a outra, ou vice-versa, de acordo com o período analisado e o ambiente macroeconômico

\footnotetext{
${ }^{12}$ As maxidesvalorizações decididas a partir do lançamento das políticas de estabilização de segunda geração, do início dos anos 1990 (Consenso de Washington), protegeram a indústria nacional, enfraquecida por anos de hiperinflação e níveis reduzidos de investimento. As empresas que haviam sofrido menos com a longa crise dos anos 1980 foram beneficiadas de tal proteção por um certo período de tempo e puderam se modernizar. As demais praticamente desapareceram. Essa proteção por meio da política cambial enfraqueceu-se por duas razões. Em primeiro lugar, com a apreciação real da taxa de câmbio seguida ao fim do diferencial de inflação em relação aos países desenvolvidos e a manutenção relativa de uma taxa de câmbio nominal. E, em segundo lugar, em função do afluxo de capitais estrangeiros, atraídos pelas altas taxas de juros reais e a segurança de poder repatriar tais recursos assim que o desejassem.

${ }^{13}$ Blazquez-Lidoy et al. (2006) mostra que a China compete especialmente com o México: a estrutura de suas exportações são bastante semelhantes e os custos de mão-de-obra são mais baixos na China do que no México. Os dois países apresentam empresas montadoras importantes, mas pode-se observar que a China tenta desenvolver a integração de determinadas indústrias, ao contrário do México. Além disso, é possível que nos próximos anos a concorrência chinesa possa ser estabelecida também em produtos de média e alta tecnologia que estejam fora do circuito das maquilladoras. A concorrência se fará, então, também em face de determinados ramos fortes no Brasil, como a indústria aeronáutica e a automobilística.
} 
(distribuição de renda, modo de inserção na economia internacional, relações com as economias mais desenvolvidas e com os mercados financeiros internacionais). No caso brasileiro, a face parasitária de Jano se impõe à sua face virtuosa, como vamos demonstrar mais à frente. A globalização no contexto brasileiro favorece o desenvolvimento de um comportamento rentista. Ressurgidos de um passado longínquo, os rentistas de hoje em dia vivem graças ao grande salto obtido pelo setor financeiro. Eles se apropriam de uma parcela expressiva das despesas públicas graças à explosão dos serviços da dívida interna, à uma parte crescente dos lucros das empresas não-financeiras em razão de seu endividamento e à elevação dos pagamentos de dividendos dos grupos empresarias.

A globalização por si só não pode ser considerada como a culpada por tal ressurgimento. Ela tão-somente precipita, no sentido mesmo químico do termo, um movimento já existente. Tal processo é pouco ou quase nada expressivo na Ásia, onde, ao contrário, assiste-se ao reforço e à consolidação do peso do empresariado industrial, ou seja, a relações mais virtuosas como mundo das finanças. ${ }^{14}$ $\mathrm{O}$ crédito e os empréstimos desempenham um papel importante no financiamento do investimento naquela região, ao contrário do que se observa no Brasil e na América Latina de uma forma geral. A taxa de formação bruta de capital fixo, por exemplo, se situa entre $30 \%$ e $40 \%$ do PIB, contra algo entre $18 \%$ e $22 \%$ para o Brasil. Nesse último, os bancos preferem alocar seus recursos nos títulos emitidos pelo Estado para financiar o serviço da dívida interna, basicamente, por duas razões: tal aplicação parece ser mais segura do que o empréstimo a empresas ou famílias com maior risco de inadimplência. As taxas de juros reais são bastante elevadas, ${ }^{15}$ o que torna tais aplicações extremamente lucrativas e limita de forma significativa a expansão do crédito em direção de empresas e famílias. Quando se tornam tomadoras de empréstimos, estas devem pagar um spread elevado — justificado pelo "risco" assumido pelos bancos ao oferecer o crédito com possibilidade

\footnotetext{
${ }^{14}$ O que não significa que o lado "vicioso" das finanças não esteja presente. Sua manifestação pode ser sentida com força à época da grave crise financeira do final dos anos 1990 na Ásia. Ela pode ser identificada hoje em dia no crescimento descontrolado dos mercados financeiros chamados "emergentes" e o crescimento extraordinário das dívidas de alto risco desses bancos.

${ }^{15}$ As razões obedecem a uma lógica monetarista. De acordo com os economistas do Ministério da Fazenda de Lula, as taxas de juros elevados deveriam servir a reduzir a alta de preços e dar sinais claros aos mercados financeiros internacionais a respeito da "seriedade" da política adotada. Acompanhada da busca do superávit primário significativo (diferença entre o total das receitas públicas e o conjunto de suas despesas, a menos do pagamento de juros do pagamento do serviço da dívida pública), tal política de metas de inflação deveria aumentar o grau de credibilidade do país e propiciar uma redução do risco país. Tal redução ocorreu, os empréstimos no exterior puderam ser realizados a custos mais baixos, mas tudo isso às custas da incapacidade de promover o crescimento econômico, de reduzir de forma significativa a pobreza, de implementar uma política social mais conseqüente, à altura das necessidades do país. E esta não era a única política possível. O Brasil é o único país da América Latina que praticou tal política e foi por isso que manteve, ao longo dos anos 2000, as taxas de juros reais, fora de cenário de crise aberta, mais altas do mundo, ao lado daTurquia. Com uma certa dose de ironia, pode-se afirmar que, sob a presidência do Partido dos Trabalhadores, o país foi mais realista que o rei, indo além das exigências do próprio FMI.
} 
de não reembolso - que se acrescenta às taxas de juros. Eles limitam assim seus empréstimos às operações de curto prazo (crédito ao consumo para as famílias e crédito para o financiamento do capital circulante para as empresas). ${ }^{16}$ Uma vez que é impossível haver crescimento na ausência do crédito de longo prazo (pode-se imaginar um capitalismo industrial sem o setor financeiro?), o governo termina por conceder uma série de facilidades para favorecer os investimentos no agronegócio, em determinados setores industriais, na habitação e outros. E tal procedimento acaba constituindo um paradoxo: de tanto querer agir de acordo com o pensamento dominante na equipe de governo, termina-se por praticar uma política seletiva de taxas de juros que se opõe aos princípios básicos desse mesmo pensamento. $\mathrm{O}$ resultado dessa política, um misto de doutrinarismo e pragmatismo, acaba sendo o fortalecimento dos comportamentos rentistas. Estes acabam favorecendo os setores de renda mais elevada da população que podem aplicar seus recursos em títulos financeiros lucrativos. Mas beneficiam, principalmente, os bancos que pouco financiam o investimento, pois preferem comprar os títulos públicos.

Esta outra destinação conferida aos fundos e recursos disponíveis, que seriam potencialmente dirigidos a empréstimos, vai se constituir em obstáculo ao investimento. E isso não apenas pelo fato das empresas não-financeiras optarem preferencialmente por alocar seus recursos em produtos financeiros, ao invés de focar no investimento fixo - "financeirizando" assim suas atividades, como se pode observar em boa parte dos países desenvolvidos. Na verdade, o fato é que tais empresas encontram um conjunto de constrangimentos de difícil superação. A dominação do financeiro sobre o produtivo se expressa pela parcela crescente, no interior dos lucros das empresas não-financeiras, de lucros financeiros (despesas de suas dívidas relativas a empréstimos de capital circulante, pagamento de dividendos, etc.) em detrimento de lucros que serviriam para o autofinanciamento. A taxa de investimento permanece não pelo fato da valorização do capital ser fraca, mas sim em função dela se situar abaixo do que propiciam os investimentos em carteira e, sobretudo, pelo fato do "apetite financeiro" se apresentar como elemento contrário às possibilidades de financiamento.

De forma mais objetiva, isso significa que no valor agregado das empresas não-financeiras cresce a parcela dos lucros brutos. Mas em seu interior cresce mais rapidamente a parcela dos lucros destinada ao setor financeiro, em comparação à parcela dirigida aos investimentos produtivos (Bruno, M., 2007). Dito de outra forma, a parte dos lucros totais das empresas não-financeiras aumenta em seu valor agregado, mas diminui quando ela se vê reduzida dos juros pagos ao setor financeiro. Ora, normalmente seria este resultado líquido o que propiciaria o autofinanciamento. A variável de ajuste acaba sendo o salário: a alta da produtivida-

\footnotetext{
${ }^{16}$ As empresas investem fazendo uso de seus fundos próprios e recorrem pouco ao crédito muito caro, à exceção das maiores entre elas que têm acesso ao mercado financeiro internacional, ou ainda quando obtêm créditos especiais por meio do BNDES para investir em setores específicos.
} 
de não retorna na forma de algum benefício aos trabalhadores. Pelo contrário, ela nutre essencialmente a voracidade das finanças. ${ }^{17}$

As dificuldades para as empresas não-financeiras se assemelham a um círculo vicioso: elas se vêem obrigadas a realizar maiores lucros para fazer face aos compromissos assumidos perante o apetite voraz das finanças. Isso pode explicar sua reticência a compartilhar com os salários os benefícios do aumento da produtividade, o que provoca ainda um distanciamento considerável entre as altas da produtividade e do reajuste dos salários. Mas essa elevação da produtividade encontra limites, uma vez que a taxa de investimento cresce pouco e a parcela consagrada à pesquisa e desenvolvimento é das mais reduzidas. ${ }^{18}$ Tais limites ao crescimento da produtividade são, em parte, ultrapassados por meio da importação de bens de equipamento de última geração e por meio de modificações na organização do trabalho. Mas eles continuam existindo no essencial e diminuem as possibilidades, a médio prazo, de se alcançar uma dinâmica de crescimento econômico elevado. No conjunto da economia, para além do setor industrial, a repartição do valor agregado total evolui em favor da renda financeira e em prejuízo dos lucros líquidos empresariais e dos salários (Gráfico 11). É esta evolução que permite a caracterização de uma economia rentista e explica, fundamentalmente, a tendência à estagnação econômica.

Além disso, é sabido que o crescimento da taxa de Formação Bruta de Capital Fixo (FBCF) tem se apresentado, em média, bastante fraco e muito volátil, apresentando vários anos com valores negativos. Dessa forma, nada mais lógico que o crescimento do PIB se apresente, da mesma forma, fraco e volátil ao longo dos últimos vinte anos.

\footnotetext{
${ }^{17}$ Dessa forma, a melhoria da competitividade e o aumento da produtividade que se segue são conseguidos com baixo investimento. Pode-se compreender o porquê de tal modernização dar-se sobretudo graças às novas formas de organização do trabalho, inspiradas em parte pelo chamado "toyotismo", e graças a uma flexibilização do trabalho baseada na precariedade e não na polivalência.

${ }^{18}$ No conjunto, incluindo-se a pesquisa pública, as despesas em pesquisa e desenvolvimento nesses países se situa entre $0,4 \%$ e $0,6 \%$ do PIB, contra mais de $3 \%$ na Coréia do Sul. É claro que não se deve limitar a tais números globais, pois é necessário levar em consideração também o "catching up" parcial de técnicas que se tornou possível pela importação de máquinas recentes e pelo salto dos investimentos estrangeiros diretos. No entanto, mesmo considerando este aspecto, o esforço permanece modesto, quando comparado aos países asiáticos.
} 


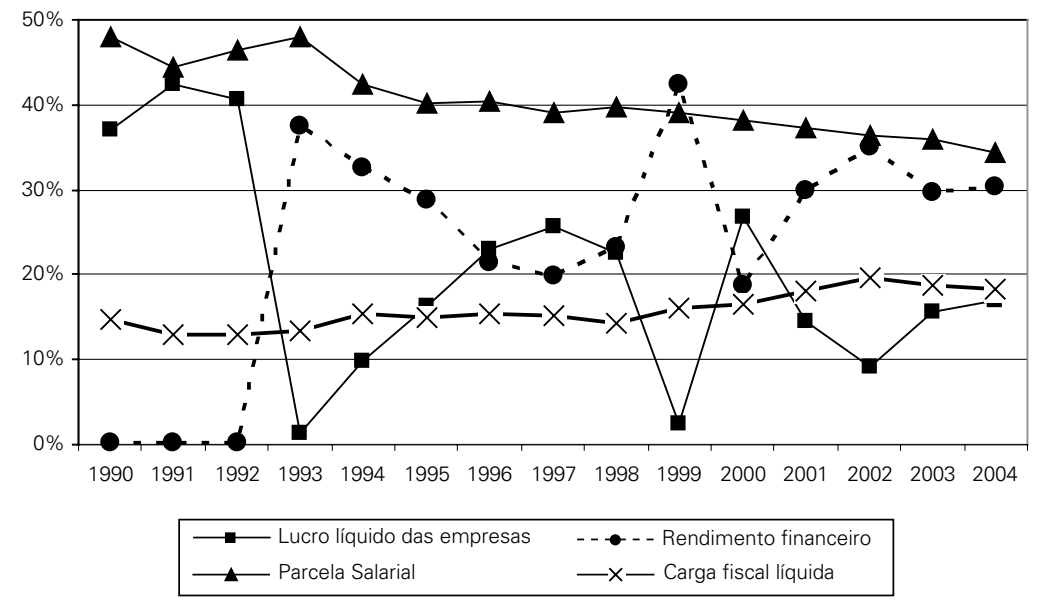

Fonte: Bruno M, (2006), os juros recebidos pelo sistema financeiro brasileiro, os salários e carga fiscal líquida foram calculados a partir de séries estatísticas do IBGE.

Nota: Os valores relativos aos aluguéis e dividendos estão incluídos no lucro líquido das empresas e, assim, eles integram a parcela dos lucros no PIB. No entanto, essa parcela não ultrpassa a média de $1,8 \%$ do valor agregado total para o período pós-Plano Real.

O valor da FBCF, em termos reais, é praticamente o mesmo em 1982 e 2005. $\mathrm{Na}$ verdade, entre 1966 e 1981, ela passou de $16 \%$ a $24 \%$ do PIB, tendo o Produto conhecido um crescimento elevado. Entre 1982 e 2005 o investimento estagnou em termos reais, o que se traduziu por uma queda em termos de sua participação relativa no PIB: ele cai de 23,4\% a 17,6\%. Assim, o esforço de investimento está longe de corresponder aos desafios impostos pela necessidade de superar os obstáculos deixados pelo "subdesenvolvimento", sobretudo se comparado ao realizado na Ásia contemporânea ou ainda aquele realizado pelo Brasil no período 1950-1970.

O diagnóstico efetuado é ainda muito otimista... Na verdade, é necessário decompor o investimento segundo a sua finalidade: habitação (construção civil), infra-estrutura, equipamento. Ora, tal decomposição não ajuda a modificar o diagnóstico realizado até o momento; muito pelo contrário. $\mathrm{O}$ investimento tende a favorecer a construção civil em relação à indústria (o investimento residencial cresceu, desde 2004, ao ritmo anual de 11,7\% — cf. Visão..., op. cit.). Mais exatamente, pode-se observar uma forte queda, ao longo dos últimos anos, nos quesitos máquinas e equipamentos dentro do estoque de capital fixo (ver Gráficos 4 e 5, no último isolando-se o peso da construção residencial). As máquinas e os bens de equipamento representavam por volta de $30 \%$ do capital fixo produtivo total em 1979, caindo para 21\% em 1990 e atingindo 17\% em 2004 (para maiores detalhes, ver Bruno, M., 2006 e Alves e Bruno, 2006). 
Gráfico 4: Evolução da parcela relativa dos componentes do estoque de capital fixo total (1950-2004)

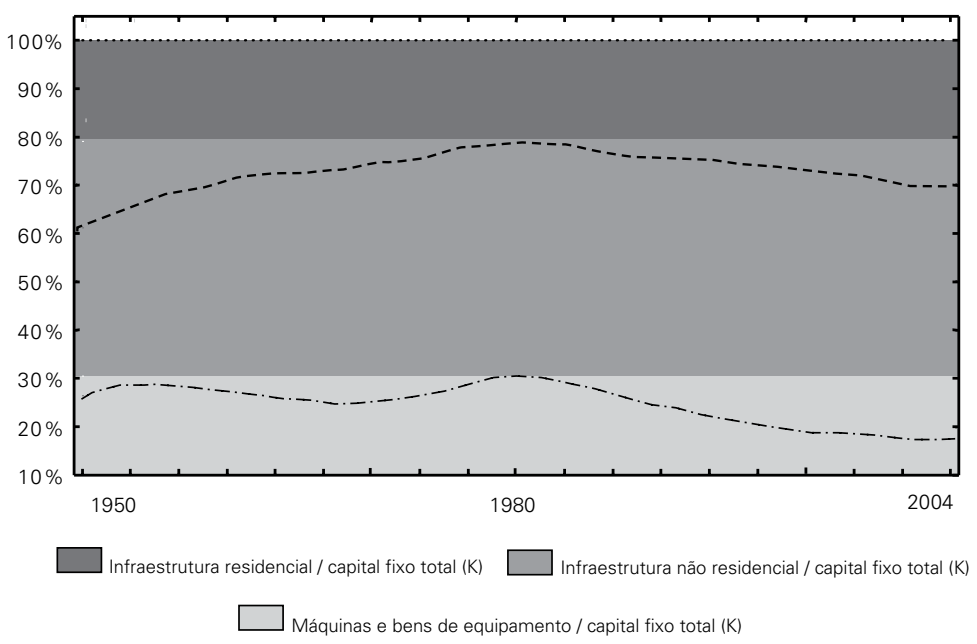

Fonte: Bruno, M., 2006, dados contruídos a partir de informações do IPEA e IBGE.

Assim, o investimento revela-se fraco, largamente insuficiente, seja em termos de seu montante global, seja na parcela relativa à compra de máquinas e infraestrutura. $\mathrm{O}$ crescimento econômico, em termos totais, não se elevou em termos de médio e longo prazos e ele não pode se apresentar de forma diversa no futuro próximo, à exceção que tal investimento seja aumentado de forma considerável e que se modifique em termos de sua estrutura interna.

Gráfico 5: Capital fixo produtivo (máquinas e bens de equipamento mais infra-estrutura não-residencial) sobre o total do estoque de capital

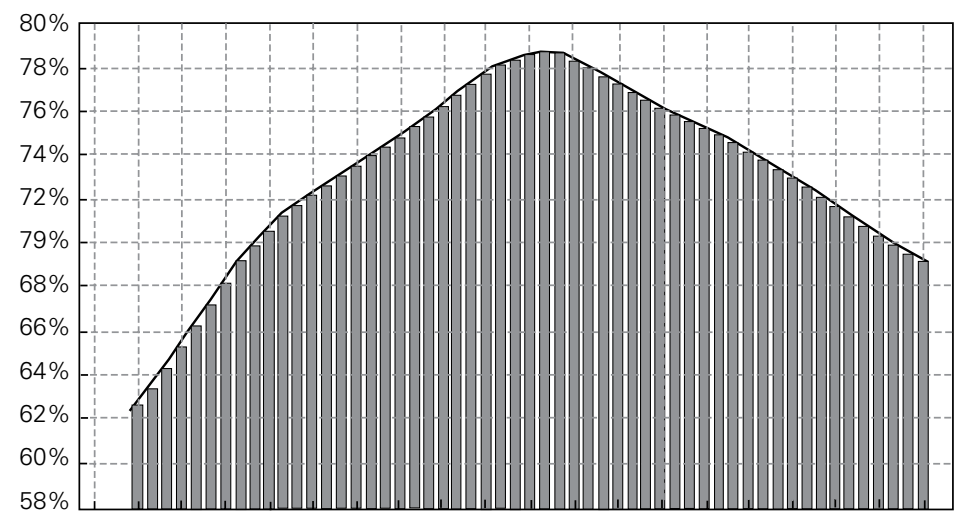

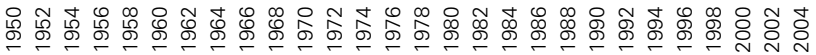

Fonte: Alves e Bruno, 2006, a partir de dados do IPEA. 
Alguns pontos de estrangulamento apareceram ao longo dos últimos anos, ao ponto que a insuficiência de infra-estrutura - em especial nos setores de energia e transportes - constitui hoje em dia um freio a uma política de recuperação do crescimento. Daí uma das razões para o lançamento do Plano de Aceleração do Crescimento (PAC) no início do segundo mandato do governo Lula, para tentar superar tal obstáculo.

\section{OS CONSTRANGIMENTOS DA GLOBALIZAÇÃO SOBRE O EMPREGO E OS NOVOS PROBLEMAS COLOCADOS PARA O GOVERNO}

Em função de razões estruturais (desigualdades muito elevadas) e de uma política monetária e comercial ortodoxa, a mundialização financeira e a globalização comercial produzem efeitos específicos sobre o emprego e as rendas. Esta seção está centrada sobre o emprego e as desigualdades salariais associadas às diferenças de qualificação.

De uma maneira geral, a evolução do emprego está ligada à demanda por trabalho das empresas e à oferta de trabalho por parte dos indivíduos. A primeira depende de diversas variáveis: o crescimento da produtividade do trabalho - que age negativamente; o crescimento do investimento - que age positivamente, mas de forma modesta, como acabamos de verificar. A oferta de trabalho depende da taxa de natalidade pretérita, mais precisamente daquelas classes etárias que entram no mercado de trabalho (que tende a baixar), ${ }^{19}$ da taxa de atividade da população feminina (que tende a aumentar). No entanto, a taxa de natalidade das classes etárias que entram no mercado de trabalho, apesar de apresentar-se em baixa, segue bastante significativa, muito mais alta do que aquela dos últimos anos. E a taxa de atividade feminina segue sendo relativamente importante hoje em dia, tendo em vista o baixo nível dos rendimentos da maioria da população brasileira.

Não se deve, porém, permanecer apenas no nível de análise macroeconômica, uma vez que a oferta e a demanda de trabalho sofrem alterações, tanto em termos de quantidade (número) quanto em termos de qualidade (qualificação).

Duas razões podem ser utilizadas para explicar que não tenha havido, ao longo dos anos recentes, um desequilíbrio acentuado entre a demanda por trabalho qualificado por parte das empresas e a oferta de trabalho qualificado e semiqualificado por parte dos trabalhadores. A taxa de crescimento econômico é reduzida

\footnotetext{
${ }^{19}$ Os demógrafos calculam os índices de estrutura por idade. O índice de estrutura é a relação entre o peso de um grupo etário na população real e seu peso na população estacionária, definida esta última como uma população de equilíbrio onde o peso de nascimentos seja igual ao de óbitos. Dessa forma, esse índice permite o cálculo do "envelhecimento" como um diferencial em relação à população estacionária e oferece também uma idéia da perda do equilíbrio demográfico na evolução entre duas datas de grupos etários. Em um futuro próximo, em função do aumento da esperança de vida e de uma baixa da fecundidade, a repartição do índice por ramo etário deverá sofrer uma inversão.
} 
e o nível de escolaridade dos jovens tem aumentado. Aliás, é esse fenômeno que explica em parte o fato de a pobreza ter recuado, simultaneamente às desigualdades salariais ao longo dos últimos anos. ${ }^{20}$ Observa-se, no entanto, uma baixa na qualidade do ensino (OCDE, 2006, Bonelli, R., 2006), que poderia ser prejudicial, caso permaneça ao longo do tempo. A oferta de trabalho qualificado pode revelarse insuficiente e pode provocar desequilíbrios no mercado de trabalho por quatro razões. Em primeiro lugar, porque a redução da taxa de natalidade começa a fazer sentir os seus efeitos. Em segundo lugar, porque a qualidade do ensino baixou e aumento quantitativo sofre alterações por tal baixa. Em terceiro lugar, o nível efetivo das despesas públicas com educação não é suficiente e sofre restrições em razão das metas de superávit primário elevado. Finalmente, a demanda por trabalho qualificado aumenta de forma expressiva. Esta última aumenta por duas razões: ela tende a aumentar mais rapidamente do que o PIB porque as restrições em termos de competitividade são mais altas em uma economia mais globalizada, caso o crescimento econômico sofra uma aceleração. Em outras palavras, pode-se considerar que, até o momento, a oferta e a demanda por trabalho qualificado puderam crescer de forma paralela e sem criar muita tensão, apesar da baixa no nível de ensino, exatamente pelo fato de o crescimento ter sido medíocre.

O desequilíbrio potencial entre a demanda por trabalho qualificado e a sua oferta só poderá ser compensado no futuro por uma melhoria no sistema educacional, ficando particularmente nos setores mais desprotegidos do sistema educativo. Caso isso não seja feito, o desequilíbrio poderá provocar os diferenciais entre as rendas destinadas aos trabalhadores qualificados e aqueles não-qualificados, acentuando ainda mais o quadro das desigualdades já elevadas, propiciando uma inversão da tendência positiva observada ao longo dos últimos anos (Rocha S., 2006 a e b). A oferta insuficiente de trabalho qualificado em relação à demanda pode, na verdade, favorecer altas de salários apenas aos trabalhadores qualificados, observados os limites das restrições impostas pela dominação do financeiro sobre o produtivo. Em sentido inverso, a oferta relativamente abundante de trabalhadores não-qualificados acentua sua exclusão social, inclusive para aqueles que logram encontrar um posto no setor formal da economia. Assim, pode-se assistir a um cenário de tensão sobre o mercado de trabalho (demanda superior à oferta) com exclusão crescente: a oferta de trabalho não-qualificada encontrando menores oportunidades de ser empregada. Caso se considere que os níveis de qualificação são mais baixos que a média nacional justamente no seio da população mais pobre, o que é uma evidência da realidade, e que tais níveis não têm evoluído favoravelmente para as crianças de famílias pobres que chegam ao mercado de

\footnotetext{
${ }^{20}$ Os dois outros fatores são o aumento substancial da política de assistência aos mais pobres e o aumento do salário mínimo. Este último se repercute sobre os aumentos das aposentadorias de valores mais baixos e a demais benefícios previdenciários, como o auxílio doença. Vários textos foram dedicados desde 2005 a esse tema. Ver, por exemplo, Neri, M.C. ( 2006), Kakwani, N., Neri M., Son H.H. (2006), Paes de Barros, R., Carvalho, M., Franco, S., Mendonça, R. (2006), Rocha, S. (2006a) e Salama (2006).
} 
trabalho, pode-se logicamente considerar que o desemprego e a exclusão dessas camadas (emprego informal, trabalho precário, trabalho a tempo parcial, baixa mobilidade social) não serão atenuados por tais transformações profundas entre a oferta e a demanda de trabalho, caso as demais variáveis não sejam alteradas. Além disso, tais desequilíbrios se traduzirão por um agravamento das desigualdades em termos dos rendimentos do trabalho, as quais se somarão àqueles existentes, uma vez que se considere o conjunto dos rendimentos da sociedade, fazendo com que a sensação de exclusão aumente.

Tal desequilíbrio poderia ser momentaneamente atenuado por uma política de gestão da taxa de câmbio visando frear, e mesmo reverter, a atual valorização do câmbio real, a exemplo da política seguida pelo governo argentino. Um câmbio mais desvalorizado protegeria um pouco mais a indústria nacional, em especial seus segmentos que utilizam mais mão-de-obra em relação ao capital. Tal processo resultaria em um aumento do emprego, ${ }^{21} \mathrm{em}$ uma diminuição da pressão sobre o emprego qualificado, em uma demanda por trabalho não-qualificado mais sustentada, de forma a diminuir ainda que de forma discreta, a exclusão a que são submetidos os mais desprotegidos. No entanto, tal opção poderia promover efeitos perversos, ao favorecer uma especialização nas indústrias com baixo conteúdo tecnológico. Ora, acabamos de verificar que tais setores não são grandes geradores de crescimento. Assim, para que tal opção seja eficaz, ela deve vir acompanhada de uma política de apoio aos setores de alto conteúdo tecnológico, com um estímulo significativo à formação de trabalhadores qualificados. A cilada da economia rentista, na qual ficaram presos os diferentes governos ao longo dos últimos quinze anos, torna ainda mais difícil romper com a lógica financeira que domina. Mas podemos considerar que o Brasil, assim como qualquer outro país,

${ }^{21} \mathrm{O}$ Brasil conheceu uma forte volatilidade em sua taxa de câmbio. A cada vez que a mesma era depreciada, manifestava-se uma tendência a aumentar a elasticidade do emprego em relação ao PIB e vice-versa. Assim foi em 1999 (crise do câmbio) e com a eleição de Lula no segundo semestre de 2002. Baltar et al. (2006) demonstram que tal elasticidade se apresenta mais acentuada durante os anos 2000 do que durante a década anterior. Ela poderia ter sido ainda mais elevada caso o governo Lula tivesse buscado frear a valorização de sua moeda. O exemplo da Argentina é interessante desse ponto de vista, uma vez à diferença do que fez Lula, o governo Kirchner reverteu a tendência à de valorização de sua moeda, no sentido contrário do que fizeram os governos Menem e De la Rúa na década de 1990. Caso não se considere os anos de crise e que se leve em conta aqueles em que o crescimento foi forte na década referida, observa-se uma elasticidade do emprego em relação ao PIB relativamente fraca, ou seja, de 0,48 . Um ponto percentual de crescimento do PIB provocaria um impacto pouco expressivo sobre a criação líquida de emprego (um pouco menos da metade), uma vez que as técnicas de produção eram cada vez mais concentradoras de capital. Esse período se caracteriza por uma forte apreciação da taxa real de câmbio, da ordem de $30 \%$. No momento em que se dá a recuperação do início do milênio com uma taxa de câmbio bastante depreciada, o emprego cresceu muito, em parte pelo fato da elasticidade do emprego em relação ao PIB ter crescido de forma expressiva. Entre o segundo semestre de 2002 e o final de 2004, ela se situou na média de 0,95 , quase o dobro da média anterior. Essa alta do emprego é devida ao ressurgimento de um processo de substituição das importações: as empresas intensivas em mão-de-obra, antes ameaçadas pela concorrência internacional, agora protegidas pela taxa de câmbio desvalorizada, retomaram contato com os lucros e estimularam a contratação de força de trabalho. 
avança por rupturas e que a acumulação de dificuldades e de problemas sociais decorrentes podem mesmo favorecer o surgimento de um "novo desenvolvimentismo" (Bresser Pereira, 2006). Ao invés de reforçar exclusivamente o papel e o peso do mercado, trata-se, por exemplo, de articular o mercado e o Estado, por meio da definição de uma política industrial determinados nichos industriais.

A mundialização não é culpada. A abertura comercial e financeira parece acentuar os comportamentos financeiros e favorecer a predominância do financeiro sobre o produtivo, de um lado. E parece dificultar os aumentos dos salários e favorecer as desigualdades entre os mesmos, de outro lado. Se fosse esse o caso, então apenas uma política protecionista permitiria a proteção do país dos efeitos negativos da globalização e o crescimento econômico deveria se apoiar apenas sobre o mercado interno, salto que poderia ser realizado com uma distribuição de renda mais igualitária. Porém, é necessário desconfiar das aparências. O aumento do grau de abertura econômica não é o responsável das evoluções aqui ressaltadas. As economias emergentes da Ásia são ainda mais abertas que a economia brasileira e, no entanto, experimentam um crescimento econômico sustentado e regular - a maior parte com alta em seu grau de desigualdades (China), outras com distribuição de renda pouco desigual e relativamente estável (Coréia do Sul). A globalização produz os efeitos que nós analisamos neste artigo pelo fato de que ela não foi controlada. Assim sendo, o debate não deve ser colocado em termos de mais ou menos globalização, e sim em termos de qual globalização estamos tratando. Uma globalização que tenha apenas como único regulador o mercado? $\mathrm{Ou}$ um globalização em que uma relação entre o Estado e o mercado possa permitir um crescimento econômico mais acentuado, uma distribuição menos desigual da renda, uma política educacional e de saúde pública à altura das necessidades do país e uma capacidade de reduzir a pobreza de forma significativa em um período de tempo relativamente curto?

\section{REFERÊNCIAS BIBLIOGRÁFICAS}

ALVEZ, J.E.D. e BRUNO, M. (2006) "Dinâmica demográfica e desenvolvimento econômico na América Latina: as lições do caso brasileiro”, mimeo, actes du colloque de Rio, UFRJ. Rio de Janeiro.

BALTAR, P., KREIN J.D., MORETTO, A. (2006) "O emprego formal nos anos recentes" in CESIT $\mathrm{n}^{\circ} 3$, Unicamp.

BANQUE MONDIALE (2006a) Global Economic Prospects, Washington, et. (2006b): rapport annuel, Washington.

BLAZQUEZ-LIDOY, J., RODRIGUEZ, J. e SANTINSO, J. (2006) “Angel or devil? China's trade impact on Latin American emerging markets”, OECD Development centre, Working paper $\mathrm{n}^{\circ}$ 252, Paris.

BNDES (2006) “Investimentos vão crescer entre 2007 e 2010”, Visão do desenvolvimento, n 21, Rio de Janeiro.

BONELLI, R. (2006) “De volta para o futuro (continuidade e mudança no Brasil dos anos 40 ao presente”, Forum Nacional, Estudos e pesquisa n ${ }^{\circ} 164$, São Paulo.

BRESSER PEREIRA, L.C. (2006) "Nouveau "developpementisme" et orthodoxie conventionnelle". Economie appliquée Tome LIX n 3 , Paris. 
BRESSER PEREIRA, L.C. (2007) Macroeconomia da estagnação-crítica da ortodoxia convencional no Brasil. São Paulo: Editora 34.

BRUNO, M. (2007) "Financiarisation et accumulation du capital productif au Brésil: les obstacles macroéconomiques à une croissance soutenue”, Revue Tiers Monde, s/n, Paris.

IEDI (2006) "Crescimento e exportação" Carta IEDI, n² 204, Brasília.

FARRELL, D. (2006) "Sizing the emerging Global Labor Market", The Mc Kinsey Quarterly $n^{\circ}$ 3, Washington.

KAKWANI, N., NERI, M., SON, H.H. (2006) "Ligações entre crescimento pró-pobre, Programas Sociais e mercado de trabalho : a recente experiência brasileira", International Poverty Centre UN et FGV, Washington e Rio de Janeiro.

LALL, S. (2005) "Rethinking industrial strategy: the role of the State in the face of globalization", in K. Gallagher, Putting development first. Londres: Zed Books.

NERI, M.C. (2006) "Miséria, desigualidade e estabilidade: o segundo Real”, mimeo, Fundação Getulio Vargas, Rio de Janeiro.

OCDE (2006) Economic Survey: Brazil, Paris.

PAES DE BARROS, R., CARVALHO, M., FRANCO, S., MENDONÇA, R.(2006): "Conseqüências e causa imediatas da queda recente da desigualdade de renda brasileira", Texto para discussão $\mathrm{n}^{\circ}$ 1201, IPEA, Rio de Janeiro.

PALMA, G. (2006a) "Globalizing Inequality: Centrifugal and Centripetal Forces at Work", DESA$U N$, Working Paper $n^{\circ} 35$, Washington; (2006b): "Growth after Globalisation: a Structuralist - Kaldorian game of musical chairs", A background paper for the World economic and Social Survey, DESA-UN, Washington; (2006c):" "Stratégies actives et stratégies passives d'exportation en Amérique latine et en Asie orientale", Revue Tiers Monde, n 186, Paris.

ROCHA, S. (2006a) Contribuções à comissão de estudos sobre desigualidades de renda no Brasil. Rio de Janeiro.

ROCHA, S. e ALBUQUERQUE (2006b) “A questão do emprego no Brasil (1996-2004)”, mimeo, Rio de Janeiro.

SABÓIA, J. (2007): “O salário mínimo e seu potencial para a melhoria da distribuição de renda no Brasil”, mimeo, UFRJ, Rio de Janeiro.

SALAMA, P. (2006): Le défi des inégalités, Amérique latine/Asie, une comparaison économique. Paris: La Découverte.

ZETTELMEYER, J. (2006) "Growth and reforms in Latin America: a survey of facts and arguments", IMF Working Papers, Washington. 